\title{
Parameters That Influence Corrosion Detection in Reinforced Concrete Based on Eddy Current Thermography
}

\author{
Lu Liu $\mathbb{D}^{1},{ }^{1}$ Dan Zheng, ${ }^{2}$ Jianting Zhou $\mathbb{D}^{1},{ }^{1}$ Juan Yang, ${ }^{1}$ and Hong Zhang ${ }^{1}{ }^{1}$ \\ ${ }^{1}$ State Key Laboratory of Mountain Bridge and Tunnel Engineering, Chongqing Jiaotong University, Chongqing 400074, China \\ ${ }^{2}$ School of River and Ocean Engineering, Chongqing Jiaotong University, Chongqing 400074, China \\ Correspondence should be addressed to Hong Zhang; hongzhang@cqjtu.edu.cn
}

Received 31 August 2019; Accepted 10 December 2019; Published 24 February 2020

Academic Editor: Carlo Rainieri

Copyright (C) $2020 \mathrm{Lu}$ Liu et al. This is an open access article distributed under the Creative Commons Attribution License, which permits unrestricted use, distribution, and reproduction in any medium, provided the original work is properly cited.

\begin{abstract}
This study introduces an eddy current thermography technique that can be used to detect and evaluate steel corrosion in a reinforced concrete structure. The rate of surface temperature changes in reinforced concrete is proposed as a means to characterize the degree of steel bar corrosion. The rate of surface temperature changes increased gradually with an increase in the corrosion degree. The influence of structural parameters on the rate of the temperature change was analyzed in detail. The results indicated that the rate of surface temperature change increased with a decrease in the concrete cover depth and with an increase in the humidity of the concrete, and this was affected by the diameter of the internal steel bar. Concrete cover was the most significant factor that affected the rate of the surface temperature change, except for the corrosion degree. The variations in the surface temperature of reinforced concrete can be explained using the law of electromagnetic induction and the electrochemical property change of corroded steel bar. This research provides a reliable basis for real-world applications and is helpful to understand the application scope of eddy current thermography technology for the quantitative detection of steel corrosion.
\end{abstract}

\section{Introduction}

Reinforced concrete structures are frequently used in bridge engineering due to their excellent mechanical and durability properties [1-3]. However, it is inevitable that some damage or defects such as concrete cracks, voids, loss of prestress, rebar corrosion, and other defects will occur in bridge structures during their construction and service periods. These internal defects will cause a great threat to the safety and durability of a structure due to their increasing severity with time and environmental conditions. Steel corrosion is considered to be the first major factor that affects the durability of a concrete structure [4-6], and it is an extremely complicated process. It is necessary to conduct nondestructive testing of steel corrosion in a reinforced concrete bridge throughout its entire life cycle due to concealment of the internal corrosion.

A large amount of research work has been conducted and many nondestructive testing methods have been proposed to detect steel corrosion in reinforced concrete [7]. These methods include the analytical method [8], the half-cell potential method $[9,10]$, the resistance probe method [11], the ray method [12], ultrasonic detection [13], and optical fiber sensing technology [14]. Although these methods have significantly progressed steel corrosion detection, some restrictions exist for their widespread use. For example, the analytical method relies on a reasonable and reliable predictive model for assessing steel corrosion [15], and the electrochemical method can only calibrate the corrosion rate but cannot detect the corrosion quantity of the steel bar $[16,17]$. A more effective and convenient technology for corrosion detection is urgently needed.

The eddy current thermography method is a nondestructive testing technology that has been developed in recent years [18]. The method is based on the principle of electromagnetic induction and infrared radiation. When a conductor is put into an alternating electromagnetic field, an eddy current is induced due to the principle of electromagnetic induction. The conductor is then heated due to Joule heating, and the surface temperature of the conductor can be recorded by employing an infrared camera. Heating efficiency is controlled by the internal material 
characteristics of the conductor, so the defect features of the object can be obtained by analyzing the temperature variations. Many researchers have conducted related research to detect structure defects [19-21], pipe leakages [22], and cracks [23]. A few groups have investigated corrosion in steel bars based on eddy current thermography, and they have found that the temperature of a steel bar is dependent on the corrosion degree of the specimens [24-27]. However, in nondestructive test methods for steel corrosion in concrete, many factors can influence the thermal properties of a steel bar buried in concrete, such as the depth of the concrete layer, the diameter of the steel bar, and the concrete's humidity. These factors can affect the corrosion detection of the reinforcement structure. The lack of research regarding the influence of these factors limits the application of these methods to quantitatively determine the corrosion degree in steel bars.

In this study, the eddy current thermography technique is applied to detect steel corrosion in a concrete structure by employing an infrared thermal camera, and the influence of the structure parameters on the surface temperature of the reinforced concrete is also discussed in detail. The study is organized as follows. In Section 2, the steel bar specimens covered by concrete are introduced, and the corrosion process is presented. In Section 3, the surface temperature for each specimen is recorded by employing an infrared thermal camera, and the experimental data are analyzed and discussed. In Section 4, the results are summarized and discussed.

\section{Preparation of the Samples}

Three series of reinforced concrete specimens were fabricated to investigate steel bar corrosion detection based on eddy current thermography. The influence of the diameter of steel bar, the concrete humidity, and the concrete cover depth on temperature variations will also be discussed. The width, height, and length of each of the concrete block specimens was $100 \mathrm{~mm} \times 100 \mathrm{~mm} \times 400 \mathrm{~mm}$, and C40 concrete was chosen to make the specimens. The depths (C) of the upper layers of the concrete in the three series of specimens were $2 \mathrm{~cm}, 3 \mathrm{~cm}$, and $5 \mathrm{~cm}$, and a schematic is shown in Figures 1(a) and 1(b). Photographs of the specimens are also shown in Figure 1(c). The diameters of the twisted steel bars were $8 \mathrm{~mm}, 12 \mathrm{~mm}$, and $20 \mathrm{~mm}$, and the rebar lengths were $45 \mathrm{~cm}$. A mold with a length of $400 \mathrm{~mm}$ was used to fix the steel bar in the right position and control the protective layer thickness accurately. All the reinforced concrete specimens were cured for 28 days under natural conditions, and detailed information for the specimens is shown in Table 1.

Accelerated corrosion was introduced to the reinforced concrete specimens using the electrochemical corrosion method. Faraday's law was used to estimate the amount of steel bar corrosion and control the corrosion process. Each specimen was soaked in a $5 \% \mathrm{NaCl}$ solution. Voltage was applied between one of the rebar ends and the preset corroded position, and the current that passed through the rebar was monitored using an amperemeter and controlled at a fixed value as much as possible. After the corrosion time reached a predetermined value, the corrosion product on the concrete surface was cleaned, and then the concrete specimen was taken out for induction heating and to record the surface temperature. To analyze the influence of the corrosion degree on the surface temperature, four corrosion times (12 hours, 24 hours, 48 hours, and 96 hours) were used. It was obvious that the corrosion degree of the steel bar increased with an increase in the corrosion time. For comparison, bare steel bars with the same diameters were corroded using the same process.

\section{Experimental Method and Results}

3.1. Experimental Method. To investigate temperature variations in the reinforced concrete surfaces heated by an electric eddy, specimens with different degrees of corrosion were placed under a high-frequency induction coil. In order to make the steel bar fast induction heating and ensure the safety of the equipment, the heating power is controlled at $90 \%$ of the maximum output power of the instrument. The current and the frequency applied to the induction coil were $61 \mathrm{~A}$ and $60 \mathrm{kHz}$, respectively. The temperature of the upper surface of the specimens was monitored using a FLIR A310 thermal camera manufactured by FLIR Systems, Inc., USA, and the distance between the coil and the specimen surface was consistent throughout the experiment. The heating time was controlled according to the surface temperature of the specimens. When the surface temperature reached $30^{\circ} \mathrm{C}$, the heating was stopped to prevent the concrete from cracking due to too high temperature. A schematic diagram of the high-frequency induction heating and infrared detection system is shown in Figure 2(a), and real photographs of the experimental setup and heating coil are also shown in Figures 2(b) and 2(c).

In addition to the corrosion degree of the steel bar, it is logical to assume that the temperature variation characteristic would also depend on the structural parameters of the reinforced concrete, such as the diameter of the steel bar, the depth of the concrete cover, and the humidity of the concrete. However, a definite relationship was not yet clear. To further investigate the influence of these factors on temperature, a series of experiments were conducted.

3.2. Influence of Corrosion Time. The surface temperatures of all the specimens were monitored throughout the experiment and saved using the FLIR A310 thermal camera. The monitor spot on each specimen was located right below the center of the induction coil and in close proximity to the upper surface of each specimen. Figures 3(a) and 3(b) show a typical raw thermograph of a specimen surface with and without the induction coil, and the measuring point for the temperature is marked as "A." A typical curve for temperature over time is shown in Figure 3(c). The temperature rapidly increases when a high-frequency current in the induction coil is turned on, and the temperature also increases during the initial stage after the excitation current is turned off until it reaches a peak. It then decreases slowly to 


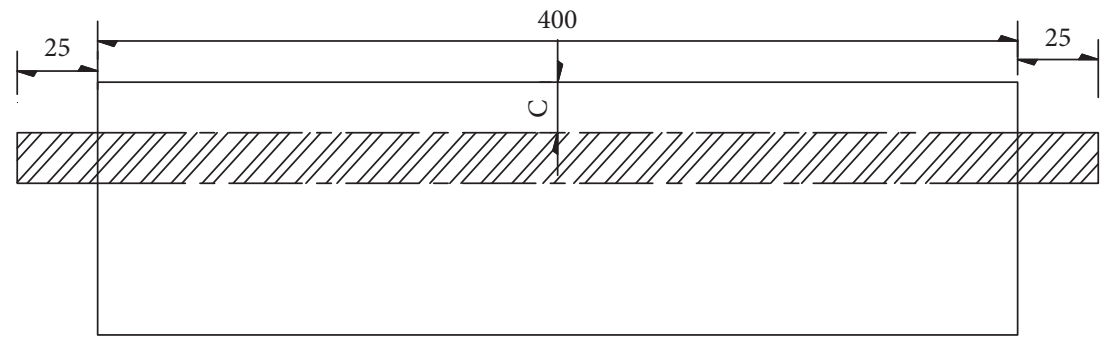

(a)

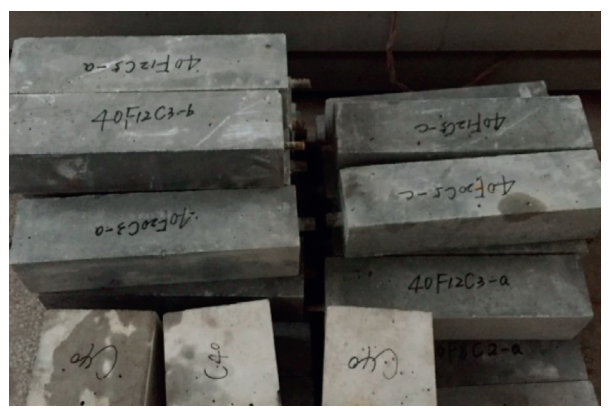

(c)

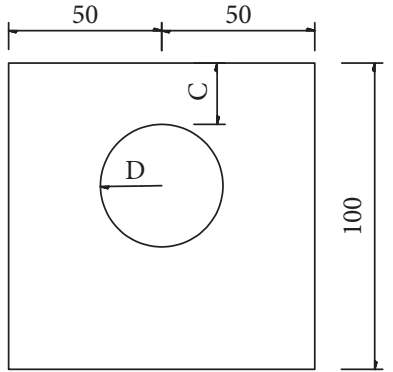

(b)

Figure 1: A lateral view (a) and a cross-sectional dimension (b) of a specimen (unit: $\mathrm{mm}$ ), and (c) a photograph of the specimens.

TABLE 1: Detailed information of the steel bar specimens covered by concrete.

\begin{tabular}{lcc}
\hline Labels & $\begin{array}{c}\text { Diameter of the steel } \\
\text { bars/mm }\end{array}$ & $\begin{array}{c}\text { Depth of the concrete } \\
\text { cover/cm }\end{array}$ \\
\hline 40F8C2 & 8 & 2 \\
40F8C3 & 8 & 3 \\
40F8C5 & 8 & 5 \\
40F12C2 & 12 & 2 \\
40F12C3 & 12 & 3 \\
40F12C5 & 12 & 5 \\
40F20C2 & 20 & 2 \\
40F20C3 & 20 & 3 \\
40F20C5 & 20 & 5 \\
\hline
\end{tabular}

room temperature with the passage of the time due to natural cooling.

This phenomenon can be understood as follows. The temperature of the internal steel bar due to induction heating is much higher than that of the concrete cover, and the temperature recorded is actually the surface temperature of the concrete cover. The heat of the steel bar is still transmitted along the longitudinal direction of the steel bar and the concrete when the eddy current has just been turned off. Therefore, the surface temperature of the reinforced concrete will continue to increase. When the heat dissipates to a critical value, the surface temperature reaches a peak, and then decreases slowly under natural cooling.

Figure 3(d) shows the temperature-time curves for the specimen labeled 40F12C2 with different corrosion degrees. It can be clearly seen that the longer the corrosion time is, the greater the rate of the temperature rise is for the concrete specimen. A similar trend was also obtained from temperature data for all the specimens, and this was introduced in detail in our previous work [27]. The results of this work indicated that the rate of temperature rise was determined by the corrosion degree of the reinforced concrete specimen, especially during the heating process that used high-frequency induction heating equipment. The rate of the temperature rise could be used as a characteristic parameter to reflect the corrosion degree of a specimen. Alternately, an approximate linear relationship between the temperature and time was found during the entire induction heating process. Therefore, a linear fitting method was used to obtain the rate of temperature rise for only the heating stage of the temperature-time curves for a specimen, as seen in Figure 3(c).

As previously mentioned, the heat induced by an eddy current in steel bar can diffuse from the inner steel bar to the covered concrete, and then to the air. The heat would dissipate in the covered concrete, so the surface temperature of a specimen would be lower than that of the inner steel bar. When a steel bar is corroded, it would be coated with the corrosion product. The heat induced by the eddy current would need to flow from the inner steel bar through the corrosion product and the concrete successively to the surface of the specimen. It is well known that the thermal conductivity $\left(1.28 \mathrm{~W} / \mathrm{m} /{ }^{\circ} \mathrm{C}\right)$ of concrete is much larger than that $\left(\sim 0.07 \mathrm{~W} / \mathrm{m} /{ }^{\circ} \mathrm{C}\right)$ of the corrosion product of a steel bar at room temperature and pressure. Due to the lower thermal conductivity of the corrosion product, the thermal diffusion rate of the corroded specimen from the inner steel bar to the cover concrete would be much lower than that of the uncorroded or lower corroded specimens. The thermal loss would be restrained, and this then would result in a higher temperature in the inner steel bar in the more corroded 


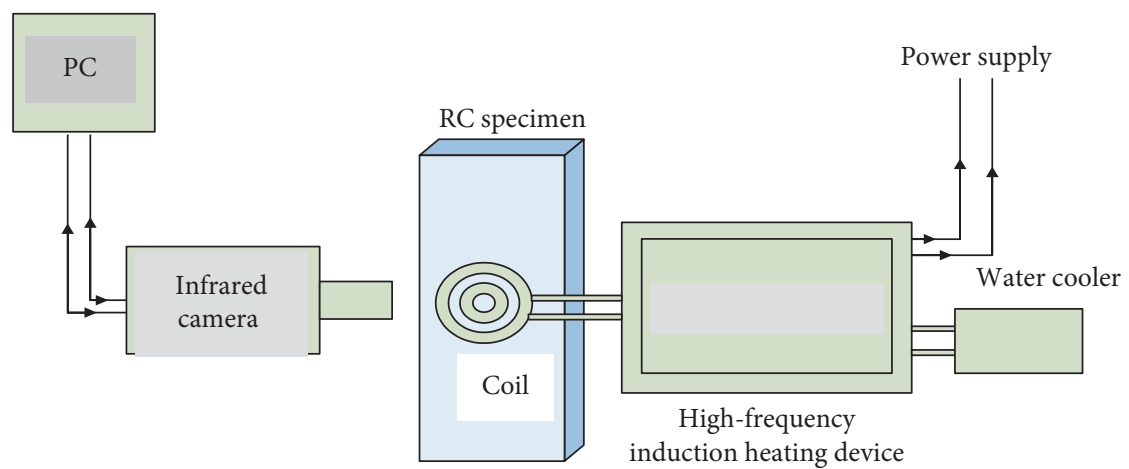

(a)

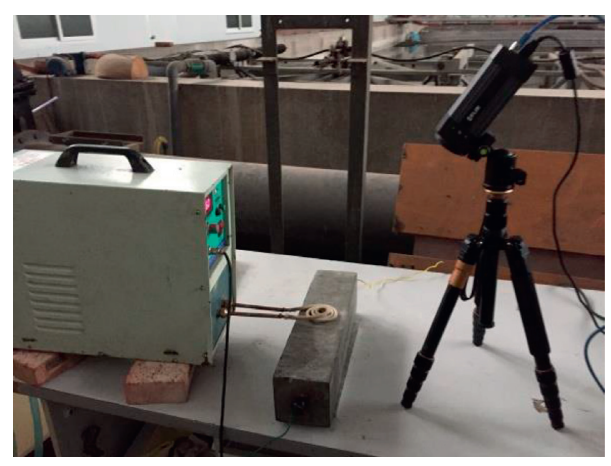

(b)

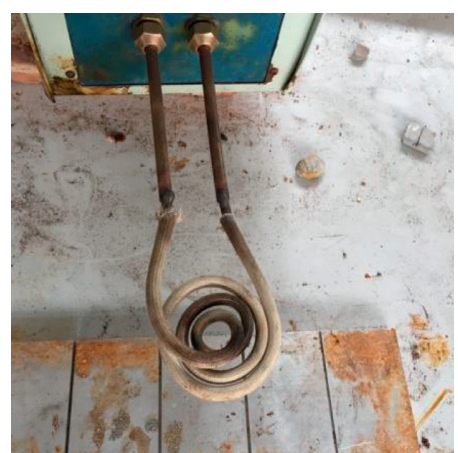

(c)

FIGURE 2: (a) A schematic diagram of the high-frequency induction heating and infrared detection system, and real photographs of (b) the experimental setup and (c) the heating coil.

specimen. Hence, a larger rate of temperature rise would occur [24]. More precisely, the corrosion product between a steel bar and concrete blocks the thermal diffusion from the inner steel bar to the covered concrete, and this would lead to a higher internal reinforcement temperature. Therefore, a greater temperature rise is obtained in more corroded reinforced concrete.

\subsection{Influence of Lift-Off Height and Concrete-Covered} Depth. When a conductor, such as a steel bar, is put into an alternative electromagnetic field, the magnitude of induced eddy current varies with the change in the distance between the source of the radiation and the conductor. The distance between the induction coil and the upper surface of the specimen is called as the lift-off height (LFH). The magnetic flux density at the position of the steel bar is exponentially attenuated with an increase in the LFH. This would greatly weaken the induced eddy current inside the steel bar; thereby the sensitivity of the induction coil would be seriously reduced. Therefore, the heating coil was always placed next to the concrete surface of the testing specimen. Hence, the lift-off height always approximately equaled zero for each measurement.

Figure 4(a) shows the surface temperature dependence on time for typical uncorroded specimens whose depth of the concrete cover was $2 \mathrm{~cm}$ and $3 \mathrm{~cm}$. It can be clearly seen that the thinner the thickness of concrete is, the faster the surface temperature changes. To clarify the effect of the depth of the concrete cover on the corrosion detection in the steel bar, Figures 4(b)-4(d) show the rate of temperature rise dependent on the corrosion time of the specimens with different concrete depths for the specimens with different steel bar diameters. The rate of the temperature rise was obtained by fitting the temperature-time curve during the induction heating stage for each specimen using the method introduced in Figure 3. All the data indicate that the depth of the concrete cover had a significant effect on the temperature growth rate at the concrete surface. The rate of the temperature rise decays rapidly when the depth of the concrete cover increases, whether the steel bar was corroded or not. By contrast, the temperature response of the concrete specimen that had induction heating applied was too weak to measure validly by experimental observation when the concrete cover depth was greater than $5 \mathrm{~cm}$. Hence, the experimental results for specimens with a concrete cover depth of $5 \mathrm{~cm}$ were unable to be detected.

It can be clearly seen in Figure 4 that the rate of the temperature rises of the concrete surface increases with an increase in the corrosion degree for all the specimens. Figure 5 shows the incremental rate of the temperature rise dependent on the corrosion time for different specimens. This is defined as the incremental rate of temperature rise when the corrosion time increases from a certain value to the next value: $\Delta K=K_{i}-K_{i-1}$, where $i$ indicates the corrosion stage.

It can be seen that the longer the corrosion time is, the greater the increment in the rate of temperature rise is for 


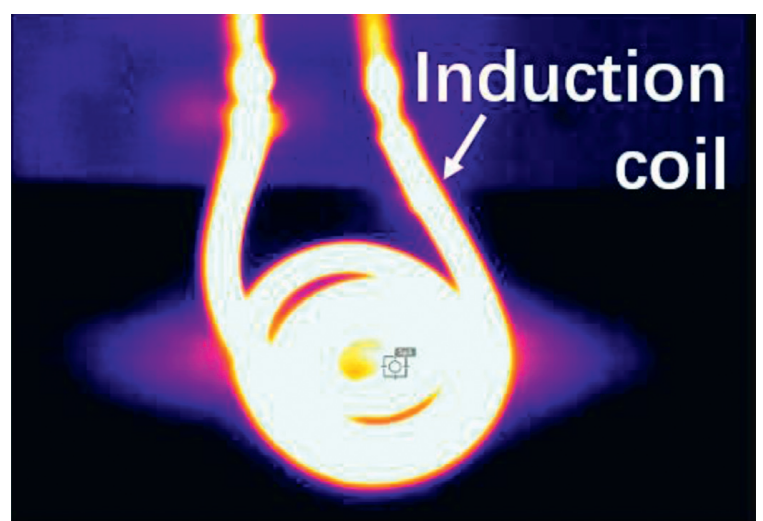

(a)

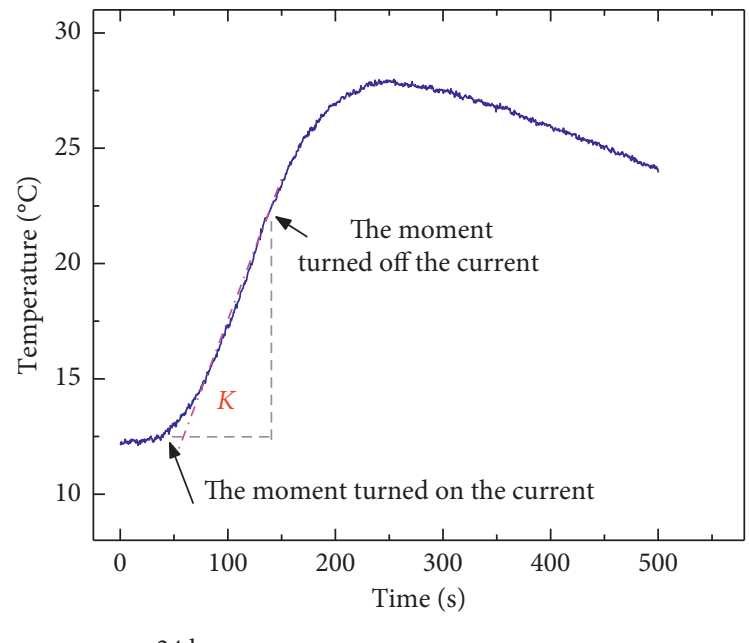

24 hours

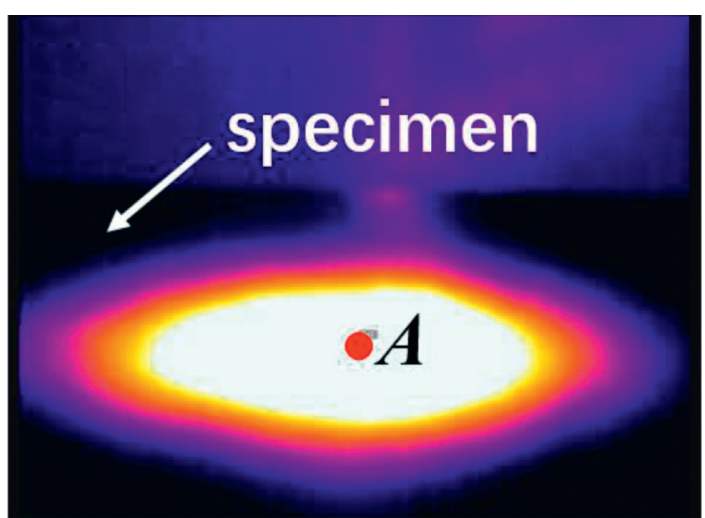

(b)

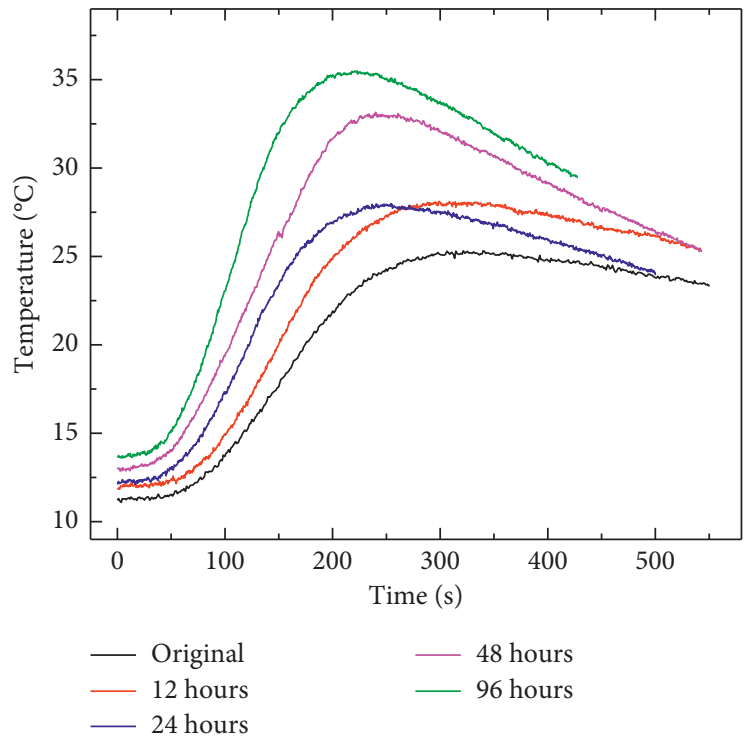

(d)

FIgURE 3: The thermograph of a sample surface with (a) and without (b) the induction coil, and the point of temperature measurement is labeled "A" in (b). (c) The surface temperature depends on the duration of the entire eddy current heating process, and the fitting line is displayed only for the heating process. (d) The surface temperature-time curves for the different corroded stages of specimen $40 \mathrm{~F} 12 \mathrm{C} 2$.

each specimen. Therefore, the incremental rate of temperature rise can also be used to quantitatively determine the corrosion degree of the internal steel bar of a reinforced concrete structure. The increment was also modulated by the concrete cover. The increment decreased rapidly with an increase in the concrete cover. For example, it decreased from the $0.076^{\circ} \mathrm{C} / \mathrm{s}$ to $0.011^{\circ} \mathrm{C} / \mathrm{s}$ when the thickness increased from $2 \mathrm{~cm}$ to $3 \mathrm{~cm}$ for the specimen that was corroded for 96 hours with a diameter of $20 \mathrm{~mm}$. This result indicated that when the depth of the concrete cover exceeded a certain level, the rate of the temperature changes due to eddy current induction heating on the concrete surface will be very small. This will lead to difficulty in detecting the corrosion degree of an internal steel bar using the eddy current thermography method when the depth of the concrete cover is too large. Fortunately, the depth of a concrete cover is approximately $3.5 \mathrm{~cm}$ under normal conditions in practical bridge engineering. Therefore, this method can be used to effectively detect internal corrosion of reinforced concrete structures in civil engineering.

3.4. Influence of the Diameter of the Steel Bar. The temperature of the concrete cover surface is also affected by the diameter of the internal steel bar in a reinforced concrete specimen. Table 2 shows the rate of temperature rise dependent on the corrosion time for different specimens with different rebar radiuses. Figure 6 shows both the rate of the temperature rise and its incremental variation with the different degrees of corrosion for specimens with different internal steel bar diameters. When the diameter of the internal steel bar was different, the rate of the temperature rise was different at each corrosion stage, and the larger the diameter of the steel bar was, the larger the rate of the temperature variation. For example, when the steel bar diameter increased from $8 \mathrm{~mm}$ to $12 \mathrm{~mm}$ and from $12 \mathrm{~mm}$ 


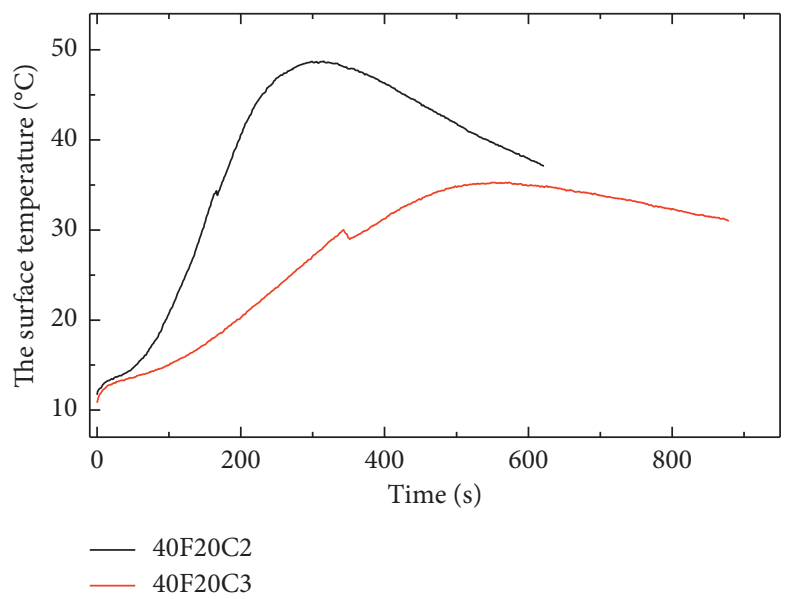

(a)

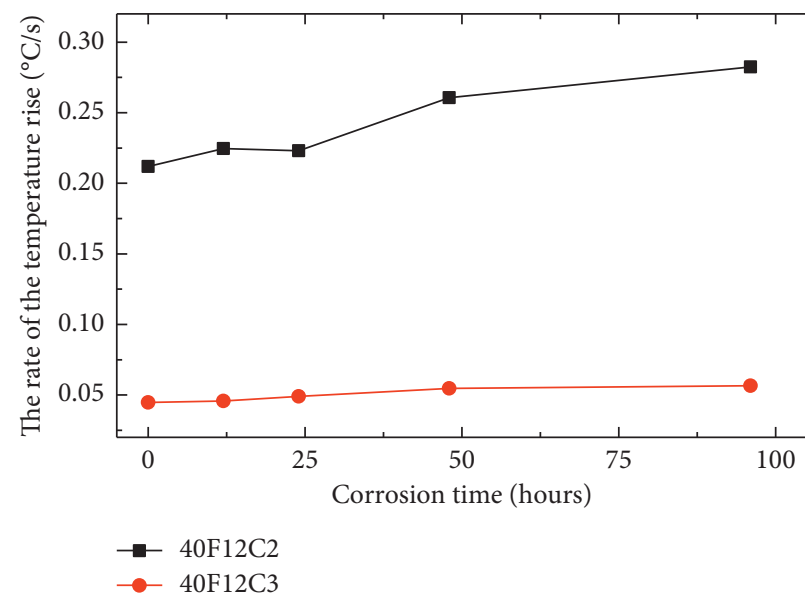

(c)

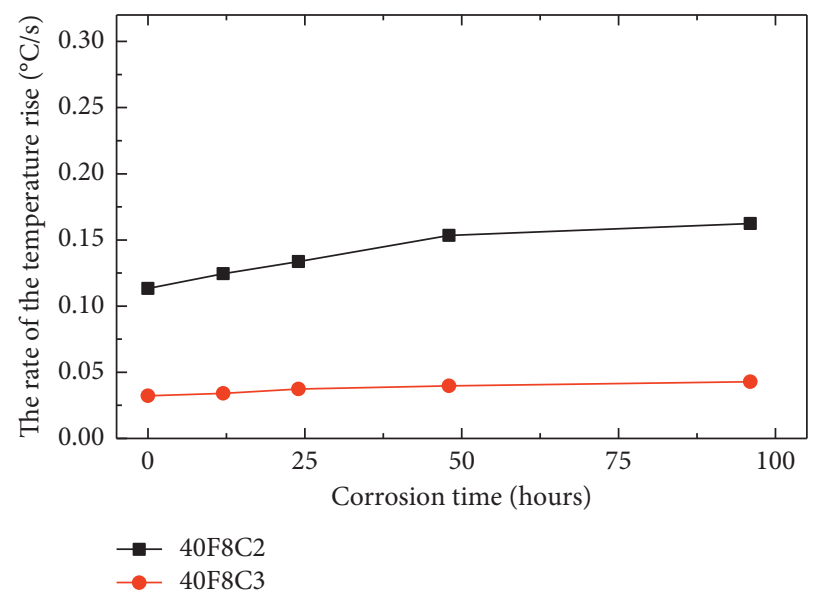

(b)

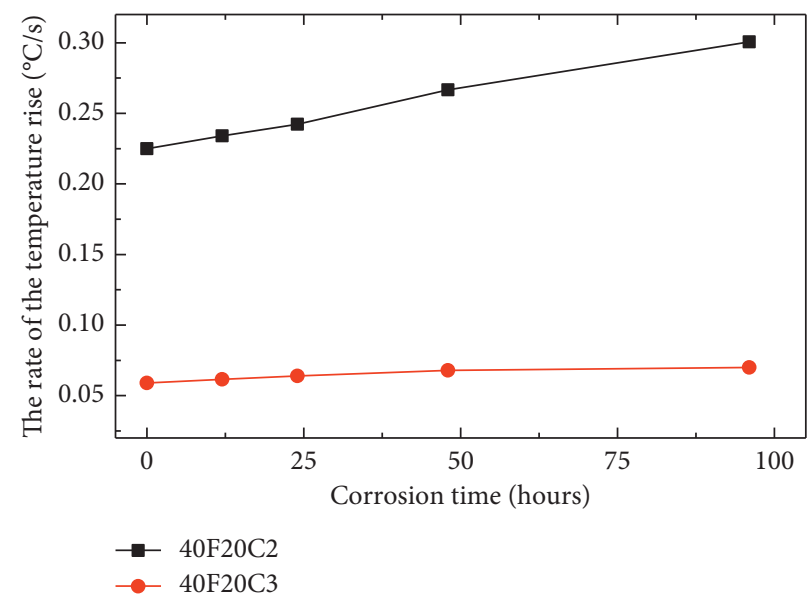

(d)

Figure 4: (a) The surface temperature depends on time for specimens with different depths of the concrete cover, and (b)-(d) the rate of the temperature rise dependence on the corrosion time for specimens with different diameters of the internal steel bar and with different concrete cover depths.

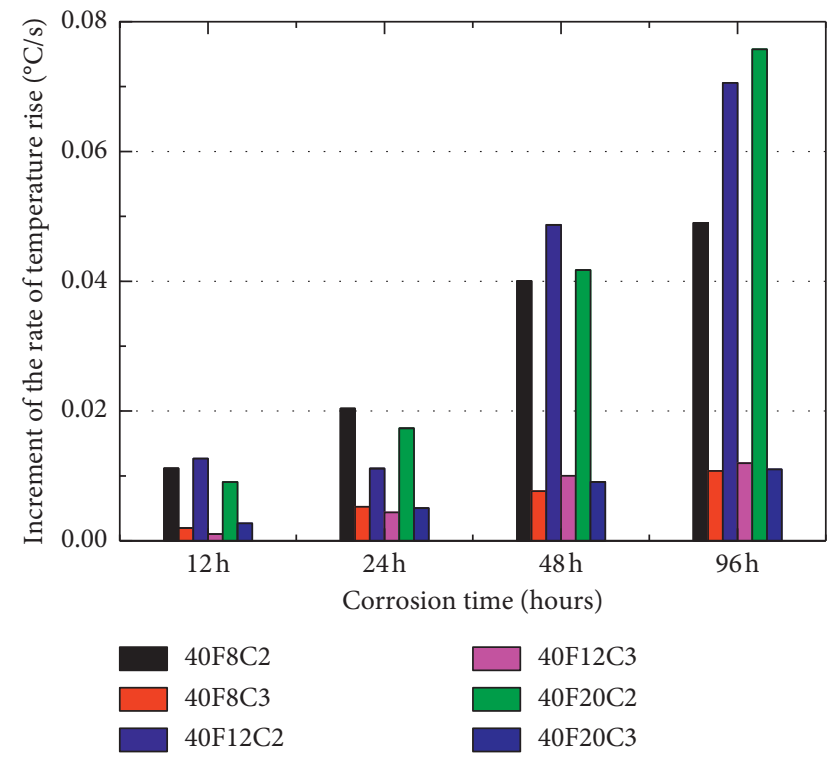

Figure 5: The incremental rate of temperature rise dependence on corrosion time for specimens with different concrete cover depths and different diameters of the internal steel bar.
TABLE 2: The rate of the temperature rise dependent on the corrosion time for different specimens with different rebar radiuses $\left({ }^{\circ} \mathrm{C} / \mathrm{s}\right)$.

\begin{tabular}{lccc}
\hline Corrosion time $(\mathrm{h})$ & $40 \mathrm{~F} 8 \mathrm{C} 3$ & $40 \mathrm{~F} 12 \mathrm{C} 3$ & $40 \mathrm{~F} 20 \mathrm{C} 3$ \\
\hline 0 & 0.03213 & 0.04467 & 0.0589 \\
12 & 0.03409 & 0.04569 & 0.0616 \\
24 & 0.03736 & 0.04905 & 0.06393 \\
48 & 0.03979 & 0.05468 & 0.06797 \\
96 & 0.0429 & 0.05662 & 0.0699 \\
\hline
\end{tabular}

to $20 \mathrm{~mm}$ for the uncorroded specimen, the rate of temperature rise increased by $39.0 \%$ and $31.9 \%$, respectively.

3.5. Influence of Concrete Humidity. To understand the effect of the humidity on temperature change, Figure 7 shows the temperature-time curves for the specimens with different water contents. The reinforced concrete specimens were soaked in $\mathrm{NaCl}$ solution for accelerated corrosion prior to the eddy current induction heating until the specimens were nearly saturated. The concrete specimens that were 


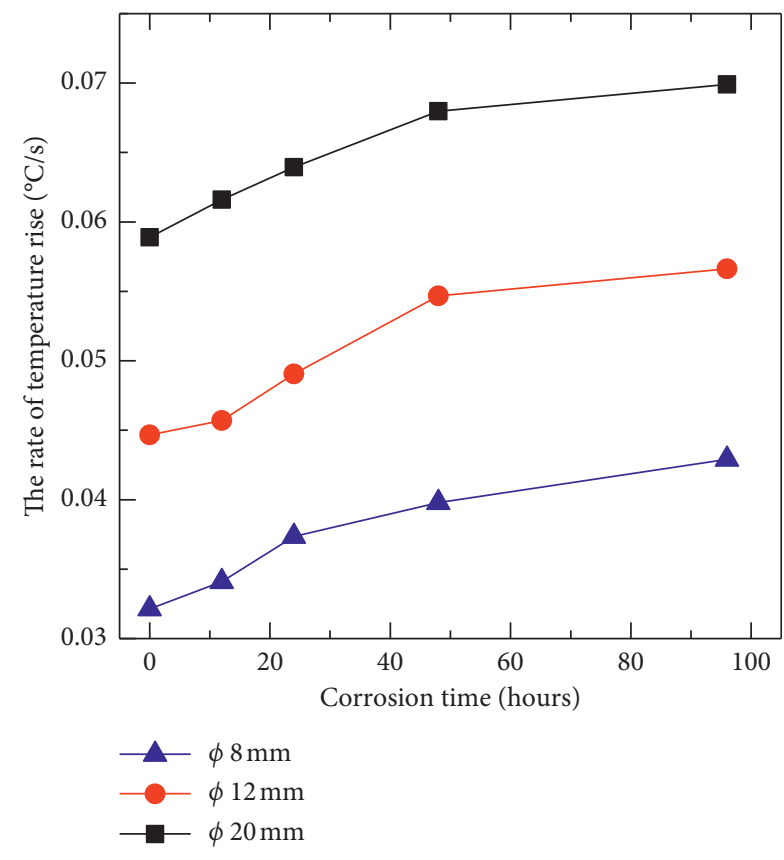

(a)

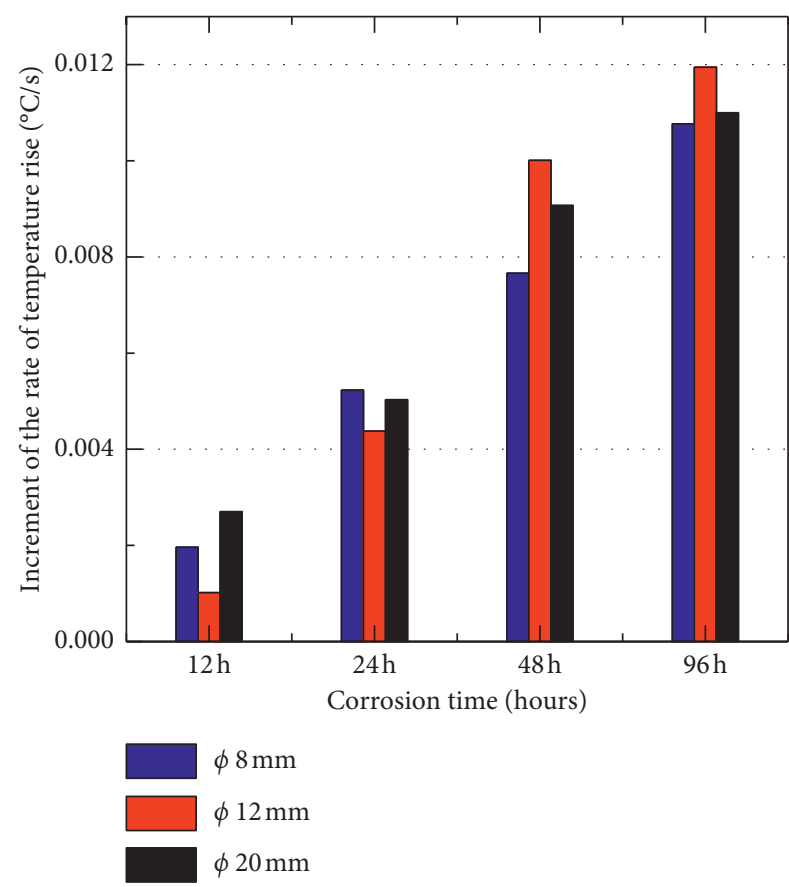

(b)

FIGURE 6: (a) The rate of the temperature rise and (b) its increment depends on the corrosion time of the specimens with different diameters of the internal steel bar.

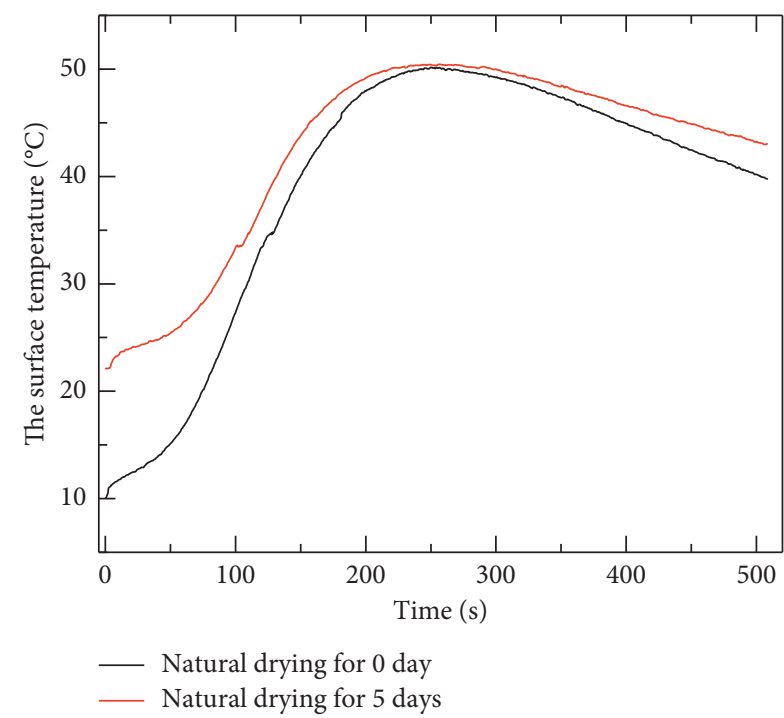

(a)

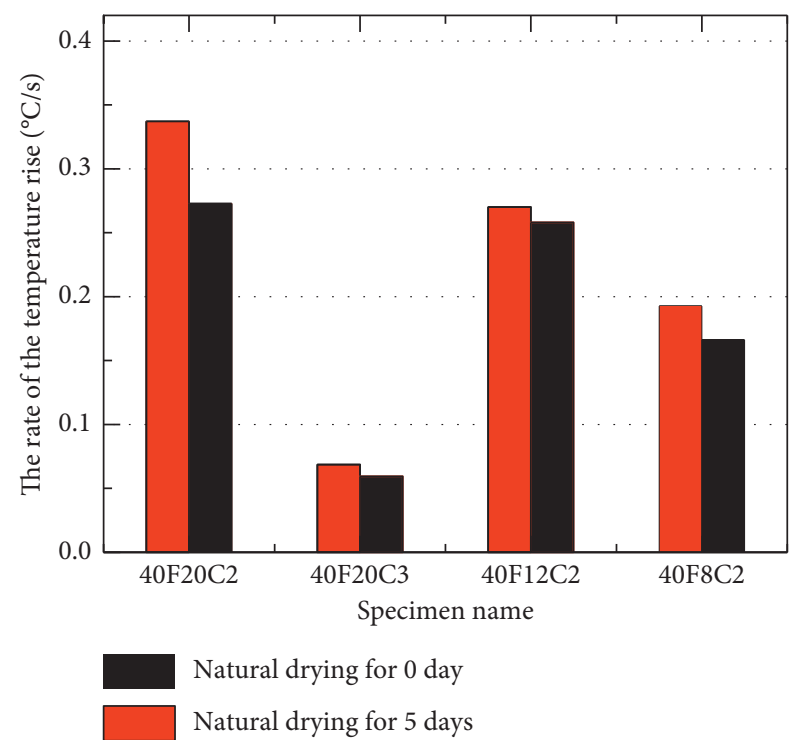

(b)

Figure 7: (a) The surface temperature depended on time for specimen 40F20C2 with different water contents in the concrete cover. (b) The rate of the temperature rise in concrete surfaces with different concrete humidity for different specimens.

corroded for 96 hours were placed indoors for five days for natural drying. The rate of temperature rise of the concrete surface increased with an increase in the water content during the heating stage. In addition, the rate of temperature drop was also greater for specimens with a higher water content due to the larger thermal conductivity of the concrete. The incremental rate of temperature rise was the greatest for specimen $40 \mathrm{~F} 20 \mathrm{C} 2$, which had the biggest internal steel bar diameter of all the specimens. The heating rate was significantly reduced when the concrete cover layer became thicker.

\section{Discussion and Conclusion}

It is easy to understand that the temperature increased rapidly due to Joule heating when a specific eddy current 
was induced to heat the specimen, and this feature was the same as the temperature change in a bare steel bar [27]. However, the trend in temperature change differed from the behavior of the bare steel bar when the eddy current vanished.

The temperature of the concrete will rise due to the heat that has been conducted to the concrete surface from the internal heated steel bar induced by the eddy current. The thicker the concrete layer is, the less heat is transferred to its surface due to the lower thermal conductivity of concrete than that of the steel bar and the thermal diffusion loss in concrete. Therefore, a thicker concrete cover resulted in a lower heating rate.

Eddy current inducted using a high-frequency alternating current undergoes a skin effect where the Joule heat is generated primarily in a skin depth range near the surface of a steel bar. With different diameters of the steel bar, both the heat-production area and the contact area between the internal steel bar and the concrete cover are different. Therefore, both the heat-generation efficiency of the internal steel bar and the heat-transfer process increase with an increase in steel bar diameters. The incremental rate of temperature rise, however, was approximately the same for specimens with different internal steel bar diameters, and it can be used to detect the corrosion degree of the steel bar with a specific diameter. For a bridge in service, fortunately, the diameter of its internal main reinforcement is generally available. On the other hand, the rate of temperature rise could be employed as a parameter for steel bar diameter discrimination because of the obvious dependency relationship.

The humidity of the concrete can affect the heatconduction process in the concrete, and it can be modified by changing the moisture content in the concrete. A higher moisture content would cause an increase in the thermal conductivity and specific heat capacity of the concrete, and this would affect the temperature distribution and the temperature rise rate of the concrete surface.

In conclusion, this study proposed an eddy current thermography technique that can be used to detect reinforcement corrosion in buried concrete. In addition, the results indicated that the rate of surface temperature changes and its incremental changes could be used to characterize the corrosion degree of a reinforced concrete structure. The influence of steel bar diameter, depth, and the humidity of the concrete on surface temperature variations was discussed. The results showed that with an increase in the corrosion degree, the rate of temperature change of a concrete surface increased gradually. By contrast, the rate of temperature change can be affected by the structural parameters of reinforced concrete, and the effect of concrete cover on temperature change was the most significant compared to the other parameters. The rate of temperature change influenced by different structural parameters was explained by the eddy current heating law and the heatconduction equation for concrete. The results provide an important reference for the application of eddy current thermography technology for corrosion detection in reinforced concrete structures.

\section{Data Availability}

The data used to support the findings of this study are available from the corresponding author upon request.

\section{Conflicts of Interest}

The authors declare that they no conflicts of interest.

\section{Authors' Contributions}

J. Zhou arranged all the work in this project and gave a keen insight in this manuscript; L. Liu and D. Zheng performed the experiments; L. Liu and J. Yang analyzed the measured data; H. Zhang and L. Liu carried out the simulation for the experimental results; $\mathrm{H}$. Zhang and L. Liu wrote the manuscript.

\section{Acknowledgments}

This work was funded by the National Key Research and Development Program of China grant number (2016YFC0802202), the National Science Fund for Distinguished Young Scholars of China (51425801), the National Natural Science Foundation of China (51808081), the Science and Technology Research Program of Chongqing Municipal Education Commission of China (KJQN201800701), and the Chongqing Natural Science Foundation of China (cstc2019jcyj-cxttX0004 and cstc2019jscx-gksbX0047).

\section{References}

[1] A. Neville, "Chloride attack of reinforced concrete: an overview," Materials and Structures, vol. 28, no. 2, pp. 63-70, 1995.

[2] G. A. Washer, "Developments for the non-destructive evaluation of highway bridges in the USA," NDT \& E International, vol. 31, no. 4, pp. 245-249, 1998.

[3] B. S. Jang and B. H. Oh, "Effects of non-uniform corrosion on the cracking and service life of reinforced concrete structures," Cement and Concrete Research, vol. 40, no. 9, pp. 1441-1450, 2010.

[4] A. A. Shah and Y. Ribakov, "Non-destructive measurements of crack assessment and defect detection in concrete structures," Materials \& Design, vol. 29, no. 1, pp. 61-69, 2008.

[5] A. Poursaee and C. M. Hansson, "Potential pitfalls in assessing chloride-induced corrosion of steel in concrete," Cement and Concrete Research, vol. 39, no. 5, pp. 391-400, 2009.

[6] A. Legat, M. Leban, and Ž. Bajt, "Corrosion processes of steel in concrete characterized by means of electrochemical noise," Electrochimica Acta, vol. 49, no. 17-18, pp. 2741-2751, 2004.

[7] D. M. McCann and M. C. Forde, "Review of NDT methods in the assessment of concrete and masonry structures," NDT \& E International, vol. 34, no. 2, pp. 71-84, 2001.

[8] B. Pradhan and B. Bhattacharjee, "Performance evaluation of rebar in chloride contaminated concrete by corrosion rate," Construction and Building Materials, vol. 23, no. 6, pp. 23462356, 2009.

[9] T. Parthiban, R. Ravi, and G. T. Parthiban, "Potential monitoring system for corrosion of steel in concrete," Advances in Engineering Software, vol. 37, no. 6, pp. 375-381, 2006.

[10] M. Pour-Ghaz, O. B. Isgor, and P. Ghods, "Quantitative interpretation of half-cell potential measurements in concrete 
structures," Journal of Materials in Civil Engineering, vol. 21, no. 9, pp. 467-475, 2014.

[11] K. Hornbostel, K. Larsen, and M. R. Geiker, "Relationship between concrete resistivity and corrosion rate-a literature review," Cement and Concrete Composites, vol. 39, pp. 60-72, 2013.

[12] S. Suzuki, S. Suzuki, E. Matsubara, and Y. Waseda, "In-situ $\mathrm{X}$-ray diffraction of corrosion products formed on iron surfaces," Materials Transactions, vol. 46, no. 3, pp. 637-662, 2005.

[13] W. Yeih and R. Huang, "Detection of the corrosion damage in reinforced concrete members by ultrasonic testing," Cement and Concrete Research, vol. 28, no. 7, pp. 1071-1083, 1998.

[14] R. Ahmed, A. A. Rifat, A. K. Yetisen, M. S. Salem, S.-H. Yun, and $\mathrm{H}$. Butt, "Optical microring resonator based corrosion sensing," RSC Advances, vol. 6, no. 61, pp. 56127-56133, 2016.

[15] J. Vrana, M. Goldammer, K. Bailey et al., "Induction and conduction thermography: optimizing the electromagnetic excitation towards application," Review of Progress in Quantitative Nondestructive Evaluation, vol. 28, pp. 518-525, 2009.

[16] H. Zhang, L. Liao, R. Zhao, J. Zhou, M. Yang, and Y. Zhao, "A new judging criterion for corrosion testing of reinforced concrete based on self-magnetic flux leakage," International Journal of Applied Electromagnetics and Mechanics, vol. 54, no. 1, pp. 123-130, 2017.

[17] J. A. González, A. Cobo, M. N. González, and S. Feliu, “Onsite determination of corrosion rate in reinforced concrete structures by use of galvanostatic pulses," Corrosion Science, vol. 43, no. 4, pp. 611-625, 2001.

[18] I. Z. Abidin, Y. T. Gui, J. Wilson et al., "Quantitative evaluation of angular defects by pulsed eddy current thermography," NDT \& E Int, vol. 43, pp. 537-546, 2010.

[19] M. R. Clark, D. M. Mccann, and M. C. Forde, "Application of infrared thermography to the non-destructive testing of concrete and masonry bridges," NDT \& E International, vol. 36, no. 4, pp. 265-275, 2003.

[20] M. Clark, D. M. Mccann, and M. C. Forde, "Infrared thermographic investigation of railway track ballast," NDT \& $E$ International, vol. 35, no. 2, pp. 83-94, 2002.

[21] D. Defer, J. Shen, S. Lassue, and B. Duthoit, "Non-destructive testing of a building wall by studying natural thermal signals," Energy and Buildings, vol. 34, no. 1, pp. 63-69, 2002.

[22] P. J. Engelbert, R. H. Hotchkiss, and W. E. Kelly, "Integrated remote sensing and geophysical techniques for locating canal seepage in nebraska," Journal of Applied Geophysics, vol. 38, no. 2, pp. 143-154, 1997.

[23] T. Sakagami and S. Kubo, "Applications of pulse heating thermography and lock-in thermography to quantitative nondestructive evaluations," Infrared Physics \& Technology, vol. 43, no. 3-5, pp. 211-218, 2002.

[24] S. Baek, W. Xue, M. Q. Feng, and S. Kwon, "Non destructive corrosion detection in RC through integrated heat induction and IR thermography," Journal of Nondestructive Evaluation, vol. 31, no. 2, pp. 181-190, 2012.

[25] B. Weekes, D. P. Almond, P. Cawley, and T. Barden, "Eddycurrent induced thermography-probability of detection study of small fatigue cracks in steel, titanium and nickel-based superalloy," NDT \& E International, vol. 49, pp. 47-56, 2012.

[26] Y. He, M. Pan, G. Tian, D. Chen, Y. Tang, and H. Zhang, "Eddy current pulsed phase thermography for subsurface defect quantitatively evaluation," Applied Physics Letters, vol. 103, no. 14, p. 144108, 2013.

[27] L. Liu, D. Zheng, J. T. Zhou et al., "Corrosion detection of bridge reinforced concrete with induction heating and infrared thermography," International Journal of Robotics and Automation, vol. 33, pp. 379-385, 2018. 